\title{
Research on Information Sharing Pattern of Agricultural Products Supply Chain Based on E-Commerce Technology
}

\author{
Zhigang $\mathrm{Li}^{1,2, *, * *}$, Yang $\mathrm{Gao}^{3}$, Yuan $\mathrm{Li}^{3}$, and Jinyu $\mathrm{Han}^{3}$ \\ ${ }^{1}$ College of Information Science \& Technology, Shihezi University, Shihezi, 832003, China \\ ${ }^{2}$ College of Economics \& Management, China Agricultural University, Beijing 100083, China \\ ${ }^{3}$ School of Economic \& Trade, Shihezi University, Shihezi, Xinjiang 832003, China \\ lzg_inf@shzu.edu.cn
}

\begin{abstract}
Taking Xinjiang's tomato industry as an example, this paper analyzes the management of agricultural supply chain and the sharing pattern results of supply chain information under the atmosphere of E-commerce both at home and abroad, illustrates problems and solutions of current tomato industry supply chain information sharing in Xinjiang, demonstrates the implementation necessity and feasibility of supply information sharing based on E-commerce technology for Xinjiang's tomato industry, and then constructs effective information sharing pattern which can improve the efficiency of Xinjiang's tomato supply chain.
\end{abstract}

Keywords: E-commerce technology, Supply chain, Sharing mode, Tomato.

\section{Introduction}

With rapid development of society and economy, particularly after China's accession to WTO, the traditional agriculture is facing severe challenges. Compared with other countries, there is no advantage of many agricultural products in both price and quality in China. Therefore, changing the current backwardness of agricultural production methods, improving the quality of agricultural products and reducing the high price of agricultural products have become the urgent need for the development of modern agriculture (Benhai Yu et al., 2006). Meanwhile, with the rapid development of electronic commerce, the development space of traditional supply chain management is widened and its meaning is broadened. Electronic commerce has changed the enterprise operation pattern and evoked the understanding of supply chain management. Development of network communications and information technology in electronic age led to the rapidly and efficiently progress of the storage, analysis, and transfer of the production and market information. To a large extent, information flow in supply chain management is no longer limited by time and space constraints. Customer, retail

\footnotetext{
* Associate Professor, The main research areas are Supply Chain Management and Information Management and System.

** Corresponding author.
} 
dealer, distribution merchant, manufacturer and supplier can share information directly. All of these greatly raised the comprehensive profit evaluation of agricultural products (Xin Liu, 2008).

Xinjiang Uygur Autonomous Region (Xinjiang for short) is located in northwest of China, which is the largest province and an important agricultural production area in China. But affected by the reason of location and economic development, its supply chain management is still defective. The great change affected by the development of e-commerce technology has resulted in the substitution of electronic commerce for traditional business activities and changed the traditional pattern of agricultural products supply chain. How to effectively and efficiently improve supply chain and how to get competitive advantages in the competitive environment of e-commerce for agricultural enterprises in e-commerce and supply chain management becomes a problem that agricultural production enterprises have to face.

Taking Xinjiang's tomato industry as an example, this paper studies how to promote the optimization of supply chain management based on e-commerce technology and supply chain management, and how to promote the information sharing of Xinjiang's agricultural supply chain.

\section{Existed Information Sharing Pattern of Tomato Industry Supply Chain in Xinjiang}

\subsection{Existed Foundation and Conditions}

In recent years, a number of enterprises of Xinjiang's tomato industry realized the role of supply-chain management, absorbed the ideas of supply chains in process of organization and management in enterprises, and had the ability to integrate supply chain management. With the continuous development of information and e-commerce technology, many companies awarded that the enterprise informatization can enhance their competitiveness and increase economic efficiency. Therefore, current Xinjiang's tomato industry has already cumulated many achievements in the information sharing of supply chain management. The continuously improved macro-environment and micro-environment provide effective support to the promote supply chain management and the efficiency in tomato industry (Jian Yu, et al., 2002).

(1) IT has been applied in Xinjiang's tomato supply chain management. Bar code technology, electronic data interchange (EDI), application identifiers are being applied, and some large tomato processing enterprises created more advanced enterprise network by using Intranet and Extranet, basically achieved information exchange and data sharing among different parts and enterprises.

(2) Leaders and staffs of tomato business improved the realization of advanced technology and improving enterprises by advanced technology. And leaders improved the cognition about staff training and the action principle of motivating mechanism.

(3) Development of supply chain management and changing of policy environment improved the conditions to develop e-commerce for Xinjiang's tomato enterprise. These years, Chinese government strongly supported the implementation of supply chain management for company and established a series of support policies. Since 
1997, e-commerce has gradually become a hot topic in Chinese social and economic activities, and the e-commerce technology and applications changed greatly as well. It creates a favorable condition to implement supply chain management based on Electronic Commerce.

(4) The outside microcosmic environment related to tomato supply chain management was improved. In recent years, the distribution, chain retail industry, retail business, warehouse and transportation business in Xinjiang have certain development. Meanwhile, the commodity logistics distribution center also developed very quickly in Xinjiang's tomato industry, which improved the link of information and kind between logistics supply chain link and terminal logistics in Xinjiang's tomato process industries.

\subsection{The Information Sharing Problems of Xinjiang's Tomato Industry Supply Chain}

Because the information sharing model of supply chain in tomato industry development is in its beginning stage, there are still many information sharing problems in the current tomato industry supply chain, as following four areas:

(1) Lack of sharing information, the overall information level is low. Because of lack of unified plan and design of information systems of the tomato market in Xinjiang, current supply chain of tomato industry had many problems: the channel of information transmission is too long, members of nodes were distributed, lost of the unified information network platform, incomplete of primary agricultural information, the development of communication network and information technology between regions is unbalance. So the informationization about the supply chain between nodes has great difference and level of information sharing is low, which leads to the low level of information sharing in whole supply chain (Hua Song, 2003).

(2) Seriously bullwhip effect and inefficiencies supply chain. At present, the problems of node enterprises are impeded information flow and isolated information. Every node enterprise in tomato supply chain arranged to maximize their own profits by respective situation and supply and order information from down-stream enterprises. In this decision mode, the node enterprises could not consider sufficiently about the status quo of tomato supply chain. The decision-making often aggravates the bullwhip effect, increases the stock of tomato products in supply chain, and decreases the overall efficiency of the supply chain system.

(3) Low integrated level inside the supply chain. Information integration means knowledge exchange between supply chain partners. This is a deeper relationship which can reduce opportunistic behavior, weaken the bullwhip effect and improve the efficiency of information. Practice indicates that information integration requires partners' deep trust, but the reduction in opportunistic behavior can enhance the trust between enterprises. In other words, reduction in opportunistic behavior is beneficial to promote the information integration, and information integration can reduce the two-way relations of opportunistic behavior (Hua Song, 2003).

But the problem of information asymmetry in the tomato supply chain has not been solved. Therefore, the possibilities of having opportunism increase, which will impact trust on relationship, reduce the degree of internal integration in the supply chain, and form an expansion vicious circle about opportunistic behavior. 
(4) Lack of funds. In order to share information, companies must invest a lot in management information system and hardware equipment, and the related personnel training, process improvement, and the readjustment of product structure will also bring high transfer cost. Moreover, data capture and data elaboration also increase the cost. Generally speaking, the higher the degree of information shares, the higher cost will be. Therefore, they need invest a large of capital in incipient stage of information sharing. It is difficult for most tomato enterprises in Xinjiang to pay such high cost for the present situation of Xinjiang's tomato industry. So the financial matter may be the problem of information sharing, although the value of information sharing is considerable.

\section{Information Sharing Construction of Xinjiang's Tomato Industry Supply Chain Based on Electronic Commerce Technology}

\subsection{The Principle of Pattern Construction}

(1) The principles of openness and absorption. Firstly, an opening pattern of agricultural information sharing should be constructed. It provides a condition that node enterprises can share information (they are suitable for exchange and sharing) with other enterprises. Secondly, it must continually rich information storage and timely track, absorb and utilize knowledge outside the supply chain.

(2) Keep balance between security and sharing. In order to realize the goal that each of chain members can share information based on protection of their core information, core competencies and competitive advantage, members can obtain new information from sharing and intercommunion and enrich their own information database. Members must determine which information needs to be kept secretly and which can be shared, and then share the information with other nodes based on this conduction.

(3) The principle of coordination. In order to maintain the high efficiency of supply chain movement, supplementary ability is requested among various members. In the field of information storage, coordinated ability in the learning capability and creation ability of information is necessary. In the aspect of enterprises' culture and the management idea, the sharing mode should have the uniformity in information sharing and communication.

\subsection{The Constructing of Pattern}

The tomato industry supply chain is not only the distribution chain, the information chain and the fund chain joint tomato supplier to consumer, but also a supply chain appreciated from processing, packing and transportation. So tomato supply chain is a rising value chain and can bring profit for related enterprise. The tomato supply chain's node enterprises must maintain synchronization, coordination, and information flow unimpeded, all of which are premise of realized rise value. Electronic commerce can realize information sharing about tomato on the whole supply chain, and take the smallest cost to provides the greatest value and the best service for the tomato consumer, which will increase operating efficiency and economic gain about tomato supply chain (Xiaolin Chen et al., 2007). 
Meanwhile, the advanced information network technology is a powerful detachment to achieve the supply chain information sharing. This technology can enhance the combinative possibility of farmers, suppliers, retails and costumers, and it is an advantage to the track, active control and the entire management about agricultural product distribution, and achieves the goal of resource and information sharing. At present, overseas agricultural product supply had used many advanced information technology. The practice indicated that the production enterprise, the department of government monitors and the third party logistic can issue and inquire related information thought Internet.

In addition, information is the neural elements of the logistics of agricultural products, only in agricultural products before, during, and even to post-storage, transportation, processing and marketing, each link also has a timely and accurate logistics information processing capacity of the premise can accurately respond to market changes. But now, because information network Xinjiang's tomato industry is not perfect, the communication channel is not smooth, and the peasant household are lived disperses, it is difficult to collect and transmit many information which seriously influenced the efficiency of Xinjiang's tomato industry supplied chains. Therefore, tomato supply chain should wildly use information network technology. Constructing management system of logistics information about Xinjiang's tomato industry should combine information technology with acceleration of the system of logistics and using of the electronic commerce. Only in this way can Xinjiang achieve information sharing of tomato supply chain.

According to the present development situation, the supply chain condition, the supply chain information sharing condition and the factors of influence supply chain information sharing of Xinjiang's tomato industry, we can construct the pattern of the information sharing about supply chain in Xinjiang's tomato industry. Main patterns are shown in Figure 1, 2, 3, 4, 5 and 6.

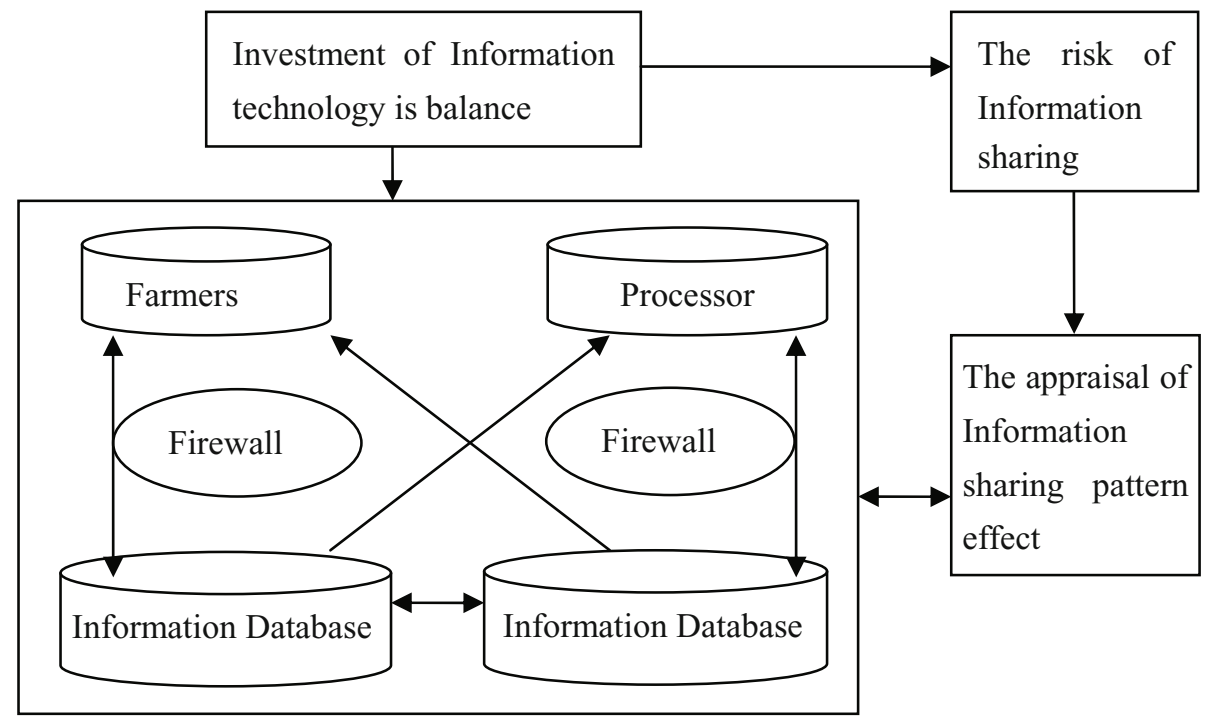

Fig. 1. Information Sharing Pattern 
As shown in Figure 1, establishment and information sharing of the two mainly databases: under governmental help, peasant household established the information database of tomato stock, origin and price. Tomato processing industry established the information database of tomato processing, demand, and quality specification. The information sharing is the data interface pattern of the point-to-point pattern between them. The peasant household and processing industry collect and transmit information from the interior and exterior of enterprise based on the Internet technology, and they use the service system visit each other's internal database, control the pattern of supply, produce and sell.

As shown in Figure 2, because most products of process tomato in Xinjiang are export, the peasant household and the overseas distributor have clear information need. The EDI pattern uses the same data standard. The output information of peasant household is the input information of overseas distributor, and they have highly accuracy and security. Therefore, the peasant household and the overseas distributor's information sharing use the EDI pattern.

As shown in Figure 3, this pattern also applied for the EDI pattern of information sharing. The information sharing of the tomato processor and the overseas distributor use the EDI special line connects with each other.

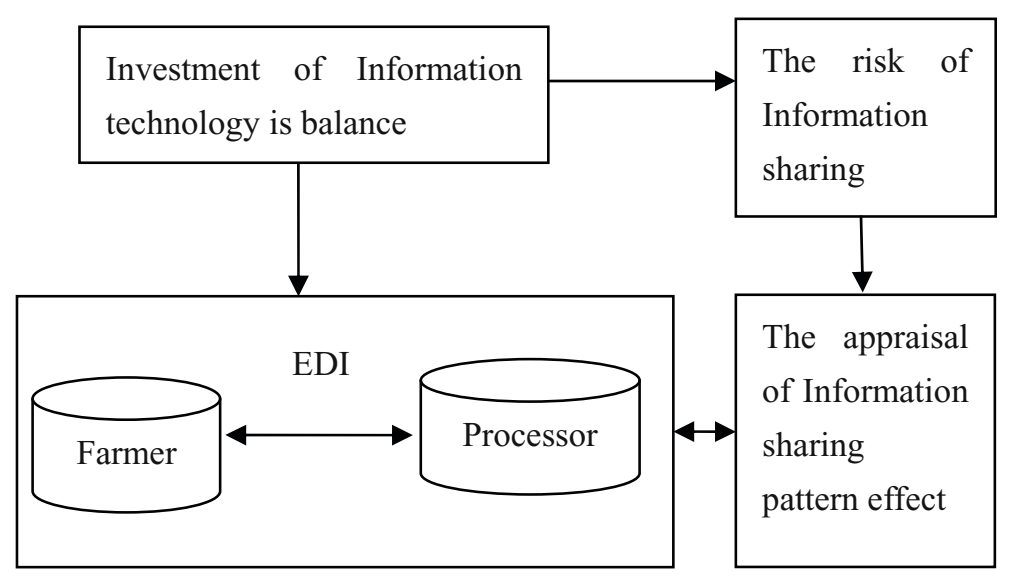

Fig. 2. Information Sharing Pattern

As shown in Figure 4, the peasant household and the tomato retail merchant share information with the EDI pattern based on their clear information need, and this pattern is highly accurate and secure.

As shown in Figure 5, this EDI pattern is used in information sharing of processor and the retailer. The EDI special line is used in the information sharing of the tomato processor and the retailer. 


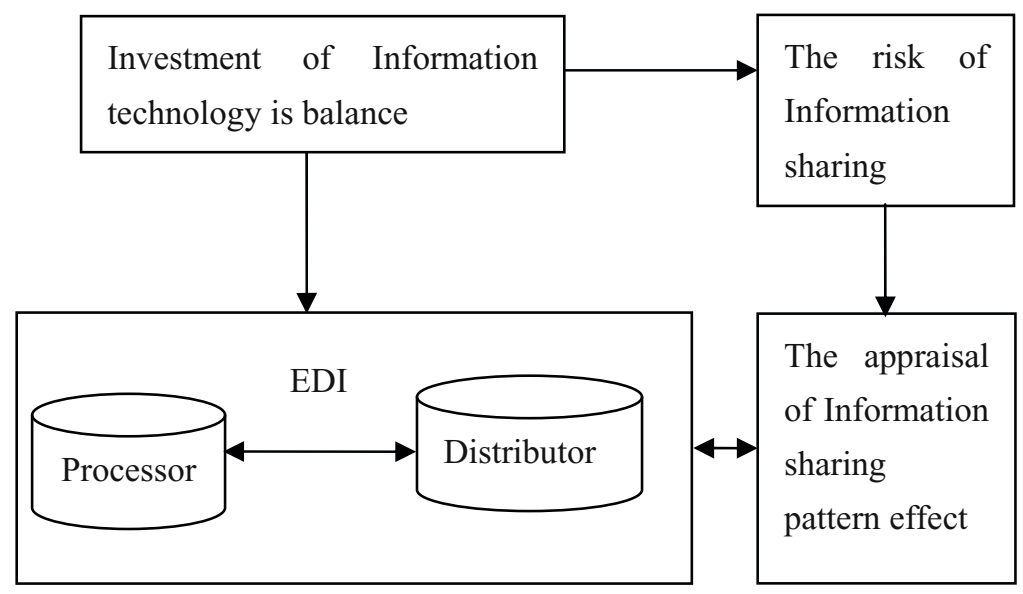

Fig. 3. Information Sharing Pattern

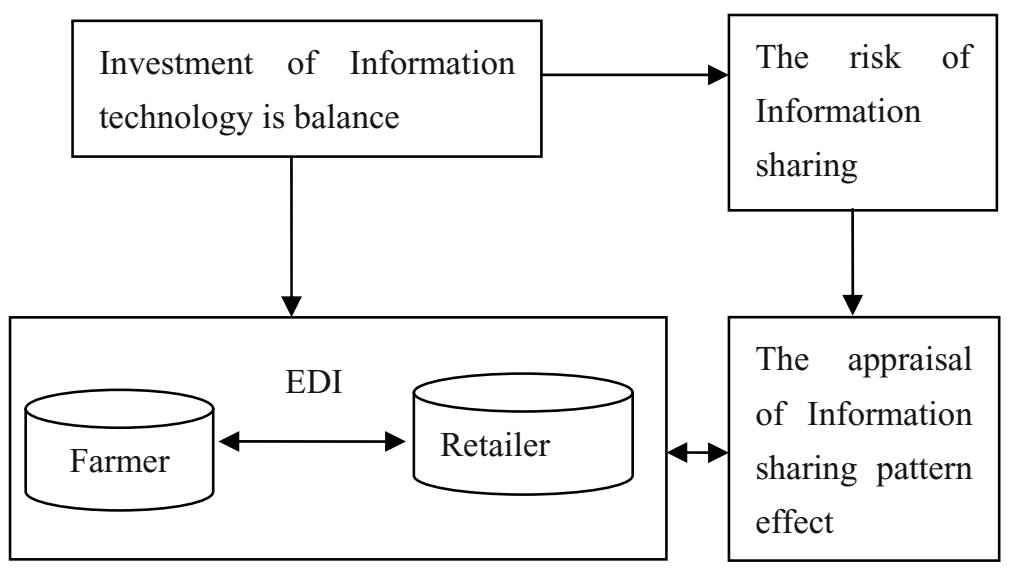

Fig. 4. Information Sharing Pattern

As shown in Figure 6, establishment and information sharing of the two mainly databases: the oversea distributors establish the database in the information of stock, price about tomato is under the government's help. The overseas retail merchant provides the tomato demand and forecast information. Information sharing between them is the data interface pattern of the point-to-point pattern.

\subsection{The Pattern's Merit}

The supply chain pattern of the tomato information sharing is based on supply chain E-business information sharing on information network. It takes the elements together including agricultural products production, processing, circulation and consume. Suppliers, farmers, industry and commerce, distributors and retailers come to be an operation of the production, supply and marketing by information sharing. By using of 


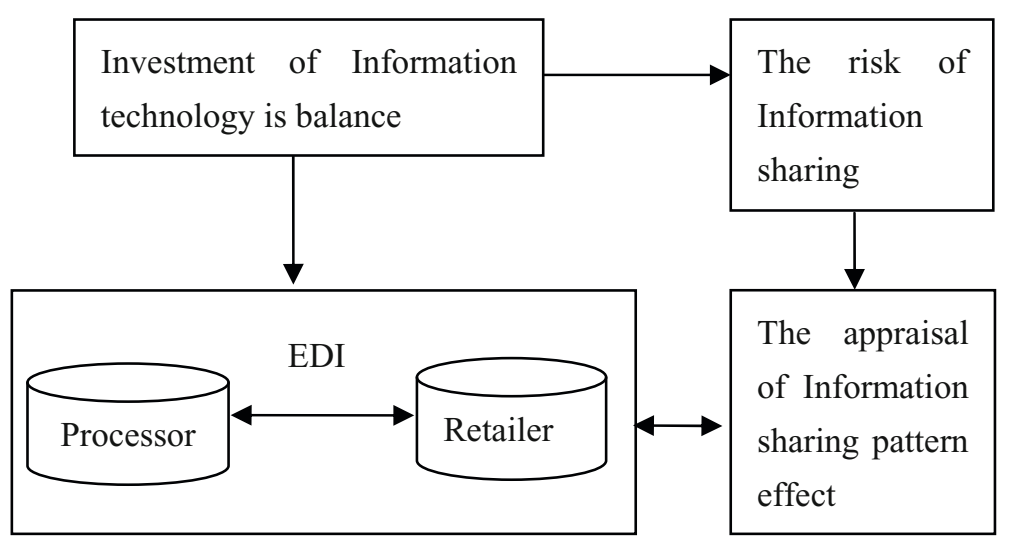

Fig. 5. Information Sharing Pattern

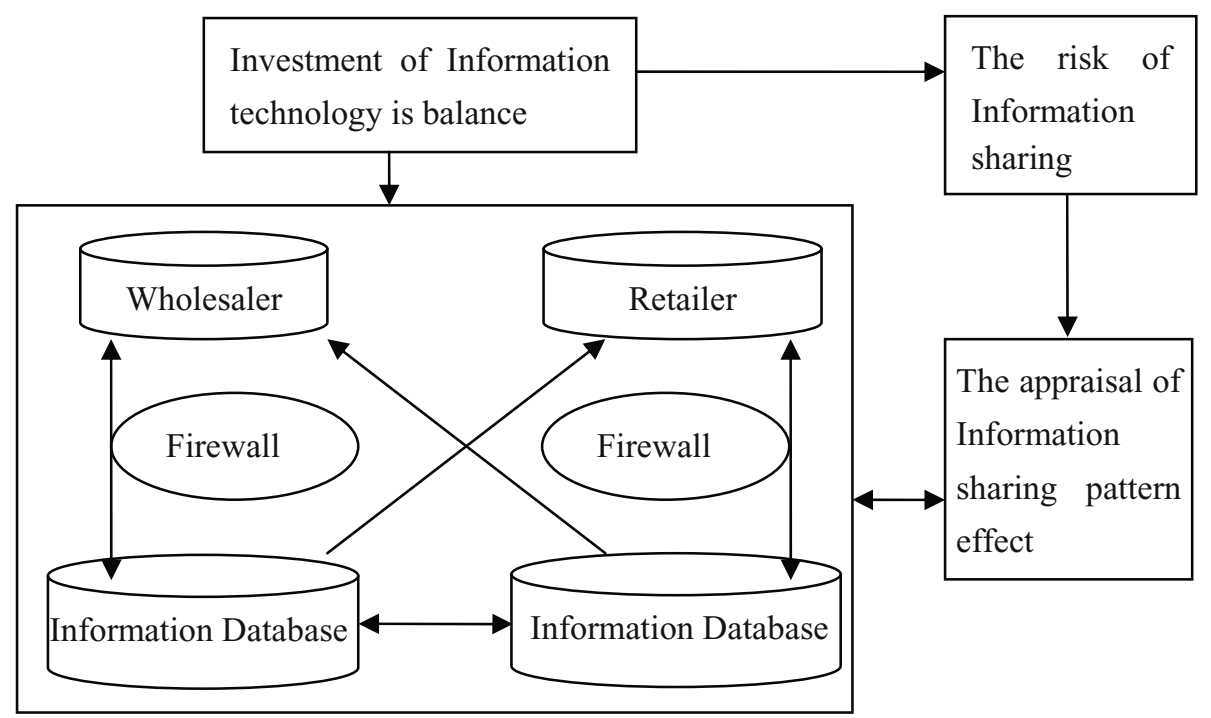

Fig. 6. Information Sharing Pattern

information sharing, growers know the production processing, the market access and quality and safety of tomato. Meanwhile, other node enterprises can promulgate the international and domestic standards about tomato in order to guide actual production (Xingdong Jiang, et al., 2006). Customers can inquire quality and safety of tomato, retrospect to grow area through the termination of information platform, in order to guarantee the consumer's rights and interests, and also be propitious to foundation and the protection of the brand about tomato. Tomato processors can share information provided by distributor and retailer through the information sharing. The processors can also transmit information about product for upstream enterprises and purchase tomatoes through order sheet. It can reduce blindness of peasant produces and 
guarantee tomato sale, not only reduce the distribution cost of tomato products and tomato loss, but also advantage to the agricultural industrial production. The tomato product supply chain can realize the advanced trading mode of on-line auction through the information platform. It also realizes on-line payment if it connects to customs and bank. There are lots of merits that information sharing pattern about tomato supply based on the environment of electronic commerce.

(1) The full supply chain information sharing, visibility throughout the supply chain The dovetail of the information systems about farmers, processor of tomato products and distributor, enhanced the flexibility of the chain management, reduced the cost and the risk of logistics management, promoted the need information about the tomato marketing arriving to node enterprise accurately and timely. In this way, agricultural production is scheduled, reduces farmer's market risk, and enhances the farmers' income.

(2) Through coordinate the information flow in supply chain, reduce the transaction cost of agricultural product circulation. Information sharing reduces tomato loss in product circulation, cycle of tomato product production, but raises the efficiency of transaction and reduced the distribution cost.

(3) Growers, processor and distributors can obtain more profit. Consumers can eat secure tomato product, and it is the material base for the development of "the order form agriculture".

(4) It improves the service quality and customer relationship. The tomato supply chain has completely collaborative management according to the consumer-customer demand. The chain uses commercial intelligence technology include DW, DDM to develop customers' knowledge, strengthen effect of marketing, optimize the service flow, improve the efficiency of working, promote customers' degree of satisfaction and loyalty, establish the long-term customer relationships and enhance the enterprises' brand.

\section{Conclusions}

The application of Xinjiang's tomato industry supply chain information sharing based on the electronic commerce technology solved the limit in time and space of tradition supply chain management, dovetailed the information systems about farmers, processor of tomato products and distributor, enhance the flexibility of the chain management, reduced the cost and the risk of logistics management, avoided the high transaction cost in the agricultural product circulating, and raised the efficiency of transaction.

It strengthened the close cooperation among the inside departments in enterprise, the enterprise and supplier, accelerated turnover rate of materials, reduced stock, lessened the fund of stock, and raised the economic effectiveness of the agricultural product enterprise.

\section{References}

1. Yu, B., Zheng, L.: Based on e-commerce technology and medium-sized enterprises to achieve material supply management system. Journal of China Management Informationization 9, 7-9 (2006)

2. Liu, X.: Electronic Commerce Supply Chain Management in China, pp. 10-16. Shandong University, Shandong (2008) 
3. Yu, J., Cao, W.: E-commerce supply chain management. Dongbei University of Finance and Economics Press, Dalian (2002)

4. Song, H.: E-commerce logistics and e-supply chain management. The Chinese People's University Press, Beijing (2003)

5. Liang, J., Tang, Y.: Information Sharing and Its Sharing Models in a Supply Chain. Journal of Industrial Engineering and Management 4, 83-87 (2004)

6. Jiang, X., Guo, J.: Constructing logistics' system of agricultural research based on the e-commerce. Journal of Marketing Management 5, 25-30 (2006)

7. Chen, X., Feng, J.: Agricultural supply chain problems of information control. Journal of Science and Management 11, 38-42 (2007)

8. Ling, N., Zhu, F.: A Study on Supply Chain Operation Mode for Agricultural Products under Electronic Commerce. Journal of Jiangxi Agricultural University: social sciences edition 5, 91-94 (2006)

9. Yin, X.: Study On the farm E-Commerce Development of Xinjiang. Bingtuan Party School Journal 1, 25-27 (2008)

10. Lin, J., Chen, Z., Fu, X.: The management of agricultural supply chain and the industrial management of agriculture, pp. 140-141. China Agricultural Press, Beijing (2006)

11. Forrester, J.W.: Industria1 dynamics. MIT Press, Cambridge (1961)

12. Lee, H., Whang, S.: The Information Sharing in the Supply Chain. International Journal of Technology Management 15, 373-378 (2000) 